\title{
The Insulin Cardioplegia Trial
}

Harold L. Lazar, MD

See related article on page 928.

From the Department of Cardiothoracic Surgery, Boston Medical Center, Boston, Mass.

Received for publication Sept 7, 2001; accepted for publication Sept 28, 2001.

Address for reprints: Harold L. Lazar, MD, Department of Cardiothoracic Surgery, Boston Medical Center, 88 E Newton St, Suite B-404, Boston, MA 02118.

J Thorac Cardiovasc Surg 2002;123:842-4

Copyright $\odot 2002$ by The American Association for Thoracic Surgery

$0022-5223 / 2002 \$ 35.00+0 \quad \mathbf{1 2 / 1 / 1 2 1 0 4 1}$

doi:10.1067/mtc.2002.121041

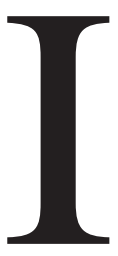

n 1965 Sodi-Pollares and colleagues ${ }^{1}$ first used glucose-insulin-potassium (GIK) solutions to treat patients with acute myocardial infarctions and found that this limited infarct size, reduced ventricular ectopy, and improved survival. Early studies in isolated heart preparations with regional ischemia showed that GIK decreased infarct size, increased high-energy phosphate levels, and improved ventricular function. ${ }^{2}$ Clinical studies in patients with acute myocardial infarction demonstrated that GIK enhanced myocardial performance. ${ }^{3}$ However, enthusiasm for GIK was dampened by a British Medical Research Council clinical trial of patients with acute myocardial infarction that failed to show any survival benefit with GIK therapy. ${ }^{4}$ In that study, GIK protocols were inconsistent, such that different doses and volumes of GIK were administered at various times from the onset of the infarct, making it difficult to determine the effectiveness of GIK therapy. The role of glucose and insulin in cardiac surgery was further diminished by the introduction of cold chemical cardioplegia and hypothermic cardiopulmonary bypass because of the inhibitory effects of hypothermia on glucose and insulin metabolism. However, the increased numbers of patients requiring urgent coronary artery bypass grafting (CABG) for acute coronary syndromes, many with reduced ventricular function, and the introduction of warm cardioplegia and cardiopulmonary bypass techniques have prompted a renewed interest in substrate enhancement with glucose and insulin in an attempt to augment myocardial protection and improve clinical outcomes for these high-risk patients.

There are several mechanisms by which glucose and insulin protect the ischemic myocardium. Although the primary energy source for the nonischemic myocardium is free fatty acids, glucose is the preferred substrate during periods of ischemia. Adenosine triphosphate derived from glycolysis is vital for stabilization of membrane ion transport, which in turn is crucial to the cellular integrity of myocytes, endothelium, and vascular smooth muscle cells. Preservation of coronary endothelial function during cardioplegic arrest has been shown to decrease ischemic necrosis. ${ }^{5}$ Glucose also esterifies intracellular free fatty acids, which decreases their toxic end-products, oxygen free radicals. Because glucose is a direct precursor of pyruvate, which is carboxylated to the citric acid cycle substrates malate and oxaloacetate, it can replenish depleted postischemic substrates, thus stimulating oxidative metabolism. Experimental studies have shown that glucose converted to pyruvate can restore contractile function through the replenishment of depleted citric acid substrates. ${ }^{6}$

Insulin benefits the postischemic myocardium by stimulating pyruvate dehydrogenase activity, which stimulates aerobic metabolism on reperfusion. Exogenous insulin helps to reverse insulin resistance during cardiopulmonary bypass, which contributes to increased serum concentrations of free fatty acids and decreased myocardial uptake of glucose. Intravenous infusions of insulin after CABG have been shown to decrease the levels of free fatty acids and increase myocardial uptake of glucose..$^{7}$ Insulin added to antegrade and retrograde tepid $\left(29^{\circ} \mathrm{C}\right)$ blood cardioplegia has been shown to stimulate aerobic metabolism during reperfusion, preventing lactate release and improving left ventricular stroke work index. ${ }^{8}$ Insulin is especially beneficial for patients with diabetes and acute coronary ischemia. Patients with diabetes are characterized by impaired glucose uptake and increased plasma levels of free fatty acids during ischemia, which leads to arrhythmias and depressed myocardial performance. Insulin enhances myocardial glucose utilization and de- 
creases free fatty acid levels in these patients. Diabetic coronary vessels tend to be prone toward vasoconstriction as a result of endothelial dysfunction resulting in decreased prostacyclin and nitric oxide production and higher levels of endothelin-1.9 Insulin upwardly regulates the L-argininenitric oxide pathway, which results in decreased vascular resistance and contributes to improved myocardial performance on reperfusion. Patients with diabetes have impaired platelet function, resulting in increased platelet aggregability, which predisposes them toward coronary thrombosis. Insulin improves platelet function and decreases plasma activity of plasminogen activator, which is increased in patients with diabetes. ${ }^{10}$

The rationale for using GIK therapy during the revascularization of acutely ischemic myocardium is based on the premise that during ischemia exogenous glucose provides increased adenosine triphosphate through glycolysis, which maintains cell viability. On reperfusion, both glucose and insulin replenish citric acid cycle substrates, which promote high-energy phosphorylation. Experimental and clinical studies have shown that substrate enhancement with GIK is most effective when periods of ischemia are followed by reperfusion. ${ }^{11,12}$ On the basis of these facts, my group reasoned that GIK might play an important role during the surgical revascularization of acutely ischemic myocardium. In an experimental study with a porcine model of acute coronary ischemia and reperfusion on cardiopulmonary bypass with cardioplegic arrest, hearts treated with GIK had a significant decrease in the incidence of ventricular arrhythmias, less tissue acidosis, better preservation of wall motion, and the lowest area of myocardial necrosis. ${ }^{13}$ Animals that received GIK during both the periods of ischemia and reperfusion did significantly better than did those receiving GIK during reperfusion only. These favorable results prompted us to perform a clinical study in which GIK was initiated during anesthetic induction and continued for 12 hours after the operation in patients who required urgent and emergency CABG. ${ }^{14}$ Patients who received GIK had higher cardiac indices, a decreased need for inotropic support, less weight gain, faster extubation times, a significantly lower incidence of atrial fibrillation, and shorter intensive care unit and hospital stays. Similar results were seen in a group of patients with diabetes undergoing $\mathrm{CABG}$ who received a modified GIK solution. ${ }^{15}$

In view of these favorable effects of glucose and insulin during $\mathrm{CABG}$, how can we explain the results of the Insulin Cardioplegia Trial reported by Rao and coauthors ${ }^{16}$ in this issue of the Journal, in which they failed to demonstrate any clinical benefit from insulin-enhanced cardioplegia for highrisk patients undergoing isolated $\mathrm{CABG}$ ? There are several flaws in the design of the study. A number of variables were not controlled for, including the temperature and route of delivery of the cardioplegia solutions and the amount of intravenous insulin used to control blood glucose levels in the placebo group. In fact, the placebo group received almost as much insulin as did the insulin cardioplegia group. Although the authors were quick to point out that subgroup analyses could find no differences between the groups when these variables were controlled for, it adds an element of bias that should not have to be addressed in such an important study. The major end points of the study, the development of myocardial infarction according to enzyme criteria and low output syndrome, are weak. Modern evaluation of outcomes after CABG should include the need for inotropic support, development of ventricular and atrial arrhythmias, weight gain, length of ventilatory support, infections (especially in patients with diabetes), and intensive care unit and postoperative hospital stays. It is not just the rate of enzyme leakage, which is unlikely to have major clinical importance in the absence of electrocardiographic or echocardiographic changes, but how completely and rapidly patients recover from $\mathrm{CABG}$ that is most important in assessing clinical outcome in today's health care system.

Despite these shortcomings, I agree with the Rao and coauthors' conclusions that the administration of insulin during a short period of cardioplegic arrest has no meaningful impact on clinical outcomes. However, I disagree with their premise that myocardial protection may not be as important as technical considerations in improving clinical outcomes for these high-risk patients. To me, the main message of this study is that our strategies for myocardial protection should not be limited to the traditional period of cardioplegic arrest but must be expanded to include other potential periods of ischemia. These include the time from anesthetic induction to the initiation of cardiopulmonary bypass and the period of reperfusion after aortic unclamping. This is why our clinical studies with GIK were so effective in improving clinical outcomes.

It would be wrong to discount the benefits of glucose and insulin for patients undergoing $\mathrm{CABG}$ on the basis of this study. If we are to improve clinical outcomes for these high-risk patients, we must not attempt to concentrate metabolic substrate enhancement only during a short period of cardioplegic arrest. As our concept of myocardial protection widens from the traditional period of cardioplegic arrest to include the pre-cardiopulmonary bypass and post-cardiopulmonary bypass periods, GIK will emerge as a safe, inexpensive, and effective therapeutic intervention in improving clinical outcomes for all our patients undergoing CABG.

\section{References}

1. Sodi-Pollares D, Testelli MD, Fisleder BL. Effects of an intravenous infusion of a potassium-glucose-insulin solution on the electrocardiographic signs of myocardial infarction. Am J Cardiol. 1965;5:166-81. 
2. Heng MK, Norris, RM, Peter T, Nisbet HD, Singh BN. The effects of glucose-insulin-potassium on experimental myocardial infarction in the dog. Cardiovasc Res. 1978;12:429-35.

3. Whitlow PL, Rogers WJ, Smith LR. Enhancement of left ventricular function by glucose-insulin-potassium infusion in acute myocardial infarction. Am J Cardiol. 1982;49:811-20.

4. Medical Research Council Working Party. Potassium, glucose, and insulin-treatment for acute myocardial infarction. Lancet. 1968;2: 1355-60.

5. Lazar HL, Bao Y, Rivers S, Colton T, Bernard S. High tissue affinity angiotensin-converting enzyme inhibitors improve endothelial function and reduce infarct size. Ann Thorac Surg. 2001;72:548-53.

6. Russel RR, Taegtmeyer H. Pyruvate carboxylation prevents the decline in contractile function of rat hearts oxidizing acetoacetate. Am J Physiol. 1991;261(6 Pt 2):H1756-62.

7. Svensson S, Svedjeholm R, Ekroth R. Trauma metabolism of the heart: uptake of substrates and effects of insulin early after cardiac operations. J Thorac Cardiovasc Surg. 1990;99:1063-73.

8. Rao V, Mississauga CN, Merrante F. Insulin cardioplegia for coronary bypass surgery [abstract]. Circulation. 1998;98(Suppl):I-612.

9. Sowers JR, Epstein M. Diabetes mellitus and associated hypertension, vascular disease, and nephropathy. Hypertension. 1995;26:869-79.
10. Davi G, Catalan I, Averna M. Thromboxane biosynthesis and platelet function in type II diabetes mellitus. N Engl J Med. 1990;322:1769-74.

11. Hearse DJ, Stewart DA, Braimbridge MV. Myocardial protection during ischemic cardiac arrest: possible deleterious effects of glucose and mannitol in coronary infusates. J Thorac Cardiovasc Surg. 1978; 76:16-23.

12. Diaz R, Paolasso EA, Pregas LS, Tajer CD, Moreno MG, Carvalan R, et al. Metabolic modulation of acute myocardial infarction: the ECLA glucose-insulin-potassium pilot trial. Circulation. 1998;98:2227-34.

13. Lazar HL, Zhang X, Rivers S, Bernard S, Apstein CS. Limiting ischemic damage during urgent revascularization using glucose-insulin-potassium solutions. Ann Thorac Surg. 1995;60:411-6.

14. Lazar HL, Philippides G, Fitzgerald C, Lancaster D, Shemin RJ, Apstein C. Glucose-insulin-potassium solution enhances after urgent coronary bypass grafting. J Thorac Cardiovasc Surg. 1997;113:354-62.

15. Lazar HL, Chipkin S, Philippides G, Bao Y, Apstein C. Glucoseinsulin-potassium solutions improve outcomes in diabetics who have coronary artery operations. Ann Thorac Surg. 2000;70:145-50.

16. Rao V, Christakis GT, Weisel RD, Ivanov J, Borger MA, Cohen G, for the ICT Investigators. The Insulin Cardioplegia Trial: myocardial protection for urgent coronary artery bypass grafting. $J$ Thorac Cardiovasc Surg. 2002;123:928-35.

\section{IN THE MOVE?}

Don't miss a single issue of the journal! To ensure prompt service when you change your address, please photocopy and complete the form below.

Please send your change of address notification at least six weeks before your move to ensure continued service. We regret we cannot guarantee replacement of issues missed due to late notification.

\section{JOURNAL TITLE:}

Fill in the title of the journal here.

OLD ADDRESS:

Affix the address label from a recent issue of the journal here.
NEW ADDRESS:

Clearly print your new address here.

Name

Address

City/State/ZIP
COPY AND MAIL THIS FORM TO:

Mosby

Subscription Customer Service

6277 Sea Harbor Dr

Orlando, FL 32887
OR FAX TO:

407-363-9661

N/ Mosby
OR PHONE:

800-654-2452

Outside the U.S., call

407-345-4000 